Without entering farther into the discussion of the theory that this affection of the bowels is the cause of continued fever, I will, in my next and concluding paper, pass on to offer a few remarks in support of the view which regards it as an effect of the fever, and of the state of the nervous and circulating systems, produced by the fever poison itself.

Evenwood, 1849.

(To be continued.)

\section{REPORT OF TWO INSTANCES OF LITHOTOMY PERFORMED UNDER THE INFLUENCE OF CHLOROFORM.}

By SAMUEL TAYLOR CHADWICK, M.D. Edin., \& M.R.C.S. Eng.

I BEG to forward you, for publication in an early number of your extensively read journal, (should you deem them sufficiently interesting, the two following cases of lithotomy, which, I think, will demonstrate the powerful agency of chloroform, not only in the alleviation of suffering, but in facilitat. ing the different steps of the operation, especially in patients of tender years.

The first case was that of a boy aged seven years, named David Morriss, who (with the exception of his calculous affection) had enjoyed good health, being remarkably robust and strong. $\mathrm{He}$ had suffered from the ordinary symptoms of stone in the bladder for nearly three years, and $\bar{I}$ performed on him the lateral operation of lithotomy last June. Both on passing the staff and binding the hands and feet he became exceedingly agitated, screaming and struggling in a most frightful manner. Mr. Mallett, who kindly assisted me at the operation, sug. gested the administration of chloroform; but as I had not taken any along with me, and the patient's residence was a short distance in the country, I proceeded without it; and before the staff was got into the bladder his struggles we e so violent as to produce prolapsus ani, and almost the entire contents of the bladder escaped. I reduced the prolapsis frequently, but the protrusion as often quickly followed. Consequently, I had to commence the incisions under somewhat embarrassing circumstances. On carrying the knife forwards in the bladder, only a few drops of urine followed the section of the prostate, certainly no evident gush; and on passing the finger to ascertain the position of the stone, before introducing the forceps, I found it strongly embraced by the coats of the bladder, and at a considerable distance from the opening in that viscus, and consequently its extraction was rendered somewhat difficult. The calculus was one of the lithates, about the dimension and figure of a common-sized walnut. The child progressed favourably, the urine passed per urethram on the eighth day, and he began to play about the house on the fifteenth.

I think the foregoing case evinces, that if chloroform had been employed, the perplexity of prolapsus, and the discharge from the bladder, would have been obviated, thereby rendering the proceedings much easier.

The second case, that of J. Lomax, six years of age, a delicate-looking child, and much emaciated, in consequence of the intense suffering that he had experienced for more than three years, from the effects of calculus vesicæ; and as there was no disease of the kidneys, the urine afforded no trace of albumen, nor any other organ, to contraindicate the operation. I performed it about three weeks after the case of Morriss; attention having been previously paid to his general health, in the way of correcting the state of the stomach and bowels, and regulation in his diet.

From the knowledge of this patient having been daily subject to prolapsus ani for several months, and his great alarm and agitation when $I$ used the sound, I determined in this case to administer the chloroform, and therefore $I$ prevailed on him to inhale it before $I$ introduced the staff, or secured him with the lithotomy tapes. Having poured about a drachm on a woollen glove, and held it lightly over his mouth and nose, he was soon sufficiently under its influence to allow of the introduction of the staff without any resistance; besides, no urine escaped from the blsdder, nor did the slightest appearance of prolapsus become manifest.

From the previous sounding I inferred the calculus to be but of small size, in which opinion Mr. Moore coincided, a gentleman who has had considerable experience in this town and neighbourhood as a lithotomist; under this impression I made a very small internal incision, which, on attempting to withdraw the stone, I found to be too limited, and therefore I had to enlarge the opening, before I succeeded in extracting the calculus. I made several ineffectual attempts to remove the stone before enlarging the opening; but after this it was perfected with great facility. The operation was necessarily somewhat protracted, and the chloroform was repeated at in. tervals, so as to keep the boy under its influence.

This calculus was likewise one of lithic acid, of an oval form and considerable size, being more than twice as large as that taken from Morriss.

In this case the urine did not pass through the urethra for a month, and for a short time subsequently there was slight incontinence.

Owing to his feeble habit and weak state of health, the early administration of quinine, with a generous diet and wine, became indispensable.

I am confident, without the aid of chloroform there would have been prolapsus in this case also, an occurrence which must always render it difficult to avoid injury of the rectum.

Bolton-le-Moors, Lancashire, Oct. 1849.

\section{ON A CASE OF HYSTERICAL PARALYSIS.} By WILLIAM THORN, Surgeon, Harrow-road, London.

If the following case of hysterical paralysis is considered worthy of insertion in the valuable pages of THE LANCET it is much at your service. I shall be glad to see it recorded therein.

Mrs. W-, a married woman, aged forty-three, having three children, the eldest twenty-one, the youngest about ten, a waistcoat-maker by trade, of a leucophlegmatic appearance, and highly nervous temperament, and subject to occasional fits of hysteria, globus hystericus very troublesome, summoned me to attend her on the 2 nd of June, 1848. I found her in a state approaching collapse, breathing extremely difficult, almost amounting to asthma, and which she supposed was brought about by the sudden news of the death of a sister, aged forty-eight, from phthisis. She was in a few days recovered from this state by opium, aperients, sinapisms, and a blister, dressed with savine ointment, and the menses returned on the 23rd, without anything particular to remark.

I ascertained, that for the last twenty years she had suffered from prolapsus uteri, appearing externally, unless supported by a broad ring pessary, which she had worn for about seven years; as it did not afford efficient support, $I$ advised the substitution of sponge, which answered much better, and was withal more cleanly; there was some leucorrhceal discharge, which materially diminished when the sponge was introduced, soaked in a mild astringent solution. There was no ulceration of the neck of the uterus.

On the 29th of September, 1848, Mrs. W- experienced her first attack of paralysis, which came on without notice, and lasted three weeks; all the limbs were paralyzed, and also the bladder, and there was great determination of blood to the brain. This attack was got under by the application of a few leeches behind each ear, and a relay on the temples, blisters the whole length of the spine, and pills containing the twelfth of a grain of strychnine every three hours. On recovering from this attack, a seton was inserted in the back of the neck, in the hope of preventing another; the futility of this was evidenced by the second paralytic attack, on the 28 th of November following, which, lasting fourteen days, was extinguished by the application of leeches to the lumbar region of the spine; blisters and pills as before. The general health was now particularly attended to, iron and quinine given, and the appearance of the patient much improved, but the third attack came on, December 19, lasting about nine days; it was removed by blisters and pills as before; the electric shock, and a strengthening plaster to the spine.

Mrs. W- was now free from an attack until January 27, in 1849 , when complete aphonia came on, (after severe globus hystericus,) which lasted three weeks, but was at length removed by stimulating gargles, application of tincture of iodine to the throat extcrnally, and a blister to the nape of the neck. Shortly after this, a violent attack of headach, with considerable determination of blood also, was removed by leeches once more behind the ears.

The menses never ceased, but were indeed quite regular to the day; occasionally there were pains of a bearing-down kind, which were only relieved by large doses of opium, followed by aperients.

Mrs. W- continued tolerably well from January (having gone to the country the latter part of the summer, for a week or two only) down to October 24, when she was again para- 